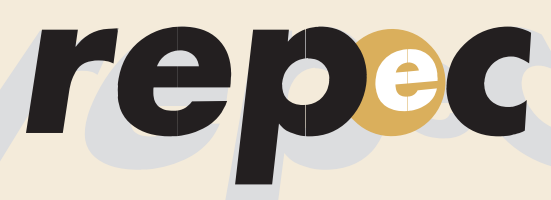

REPeC, Brasília, v. 8, n. 3, art. 2, p. 251-270, jul./set. 2014 Disponível online em www.repec.org.br DOI: http://dx.doi.org/10.17524/repec.v8i3.1034
Revista de Educação e Pesquisa em Contabilidade Journal of Education and Research in Accounting Revista de Educación e Investigación en Contabilidad

Periódico Trimestral, digital e gratuito publicado pela Academia Brasileira de Ciências Contábeis

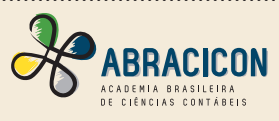

\title{
O Papel Certificador dos Fundos de Private Equity e Venture Capital Sobre a Qualidade das Empresas Estreantes na BM\&FBovespa
}

\begin{abstract}
Resumo
O presente estudo verificou, sob a perspectiva da teoria de sinalização, o papel certificador dos fundos de Private Equity e Venture Capital, sobre a qualidade das empresas estreantes na BM\&FBovespa (IPOs). Para isso, propôs-se um estudo de evento visando constatar a existência de retornos anormais acumulados (proxy para qualidade dos IPOs) em carteiras de investimentos compostas por ações provenientes dos IPOs realizados na BM\&FBovespa, no período de janeiro de 2004 a dezembro de 2007. As hipóteses do trabalho foram verificadas por meio de três procedimentos distintos: teste de médias, CAPM e regressões CAR. Verificou-se que empresas que receberam aportes de Private Equity e Venture Capital apresentaram médias de retornos anormais acumulados estatisticamente superiores às das empresas não investidas. Os resultados das regressões indicam que quanto maior a participação dos fundos de PE/VC melhor o desempenho de longo prazo dos IPOs. As evidências encontradas sugerem que a presença de fundos de PE/VC nas empresas estreantes na BM\&FBovespa possui efeito positivo sobre os retornos anormais acumulados dos IPOs.
\end{abstract}

Palavras-chave: Investimentos; Private equity; Venture capital; Bovespa; Oferta pública inicial.

\section{Carlos Henrique Rodrigues Testa Mestre em Ciências Contábeis pela Universidade de São Paulo, analista de Private Equity, Caixa Econômica Federal. Contato: Av. Paulista 2.300, 11 ${ }^{\circ}$, Bela Vista, São Paulo-SP - CEP.: 01310-300. E-mail: chrtesta@gmail.com}

\section{Gerlando Augusto Sampaio} Franco de Lima Livre-Docente em Ciências Contábeis pela Universidade de São Paulo, professor Associado da Universidade de São Paulo. Contato: Av. Prof. Luciano Gualberto, 908 - FEA 3 - Cidade Universitária - São Paulo-SP, CEP.: 05508-900. E-mail: gerlando@usp.br 


\section{Introdução}

Nos últimos dez anos, mais de cem empresas estrearam na bolsa brasileira (IPOs), perfazendo um volume de mais de $\mathrm{R} \$ 130$ bilhões em novas captações. Nesse contexto, destaca-se o aumento da quantidade de investidores individuais, também chamados de pequenos investidores, na bolsa de valores. De 2004 a 2012, o número passou de cerca de 117 mil para 587 mil, de acordo com o balanço de operações de dezembro/2012, divulgado pela Bolsa de Valores de São Paulo [BM\&FBovespa] (2013). Esses investidores possuem suas economias aplicadas tanto em empresas já listadas em bolsa como nas companhias estreantes (IPOs), objetivando auferir ganhos por meio da distribuição de lucros (dividendos e juros sobre capital próprio) ou da valorização do capital investido.

Estudos (Ritter \& Welch, 2002; Silva \& Famá, 2011) encontraram evidências de que o retorno de longo prazo das empresas estreantes na bolsa é inferior ao de empresas similares já listadas. Tal anomalia, denominada long-run underperfomance, é associada a fatores como: gerenciamento de resultados em períodos pré-IPO (Teoh, Welch, \& Wong, 1998); excesso de confiança dos investidores em períodos favoráveis da economia (Ritter \& Welch, 2002); oportunismo dos controladores e assessores financeiros para realizarem IPOs em momentos de otimismo dos mercados (Daniel, Hirshleifer, \& Subrahmanyam, 1998); e assimetria informacional nos processos de IPO (Ritter, 2003).

Pesquisas que buscam explicar o desempenho dos IPOs sob a perspectiva da teoria da Sinalização podem contribuir para a investigação desse fenômeno (Certo, 2003). Conforme Spence (1973), a teoria da Sinalização lida com os problemas de assimetria informacional nos mercados e procura evidenciar como tal assimetria pode ser reduzida com a sinalização de mais informação. Dessa forma, no contexto dos IPOs, estudos demonstram que a reputação dos underwriters e auditores (Carter, Dark, \& Singh, 1998) e a presença de fundos de Private Equity e Venture Capital (Megginson \& Weiss, 1991; Brav \& Gompers, 1997; Minardi, Ferrari, \& Tavares, 2013) servem como sinais para certificar a qualidade da empresa emissora, aperfeiçoando, assim, o desempenho do IPO.

Observa-se, nos IPOs realizados na BM\&FBovespa, uma evolução do número de empresas investidas por fundos de Private Equity e Venture Capital (PE/VC). Ao aportarem recursos, os fundos de $\mathrm{PE} / \mathrm{VC}$ adquirem participações nas empresas investidas, por meio de ações (ordinárias ou preferenciais), quotas de participação, debêntures conversíveis, opções, bônus de subscrição ou warrants. Essas empresas passam a ser monitoradas pelos gestores dos fundos de PE/VC que, por meio da participação ativa nos conselhos de administração e nas operações das companhias, resolvem ou minimizam alguns problemas centrais, que se caracterizam por grande assimetria de informação e problemas de agência (Lerner, Hardymon, \& Leamon, 2009).

Diversos trabalhos (Barry, Muscarella, Peavy, \& Vetsuypens, 1990; Megginson \& Weiss, 1991; Brav \& Gompers, 1997) dedicaram ao estudo do papel das organizações de PE/VC, e do seu efeito sinalizador no processo de abertura de capital das empresas em bolsa de valores (IPO), encontrando evidências de que nesse estágio as empresas investidas por $\mathrm{PE} / \mathrm{VC}$ se diferenciam positivamente das demais.

Percebendo a importância do tema e o aumento do número de pequenos investidores que aplicam suas poupanças nas empresas estreantes na bolsa brasileira, esta pesquisa verificará, sob a perspectiva da teoria da Sinalização, se a presença de fundos de PE/VC pode certificar a qualidade dos IPOs. Para isso, formularam-se as seguintes hipóteses:

Ha: A presença de fundos de Private Equity e Venture Capital nas empresas estreantes na BM\&FBovespa certifica a qualidade dos IPOs.

Hb: Quanto maior a participação acionária dos fundos de Private Equity e Venture Capital nas empresas estreantes na BM\&FBovespa maior a qualidade dos IPOs. 


\section{Referencial Teórico}

Estudos apontam evidências de que, ao investir em IPOs, aqueles investidores que mantiverem os ativos adquiridos no IPO podem incorrer em perdas em longo prazo (Ritter \& Welch, 2002; Silva \& Famá, 2011).

Tal fenômeno, denominado long-run underperfomance, é caracterizado pelo retorno anormal inferior de médio e longo prazos, evidenciando relevante perda de valor das ações de empresas que realizaram IPOs e/ou Seasoned Equity Offerings (SEOs), tanto em termos econômicos quanto em nível de significância estatística (Silva \& Famá, 2011).

O fenômeno long-run underperfomance pode ser atribuído a fatores como: assimetria informacional nos processos de IPO (Ritter, 2003); excesso de confiança dos investidores em períodos favoráveis da economia (Ritter \& Welch, 2002; Silva \& Famá, 2011); gerenciamento de resultados em períodos pré-IPO (Teoh et al., 1998); e oportunismo dos controladores e assessores financeiros para realizarem IPOs em momentos de otimismo dos mercados (Daniel et al., 1998; Silva \& Famá, 2011).

A teoria da Sinalização lida com os problemas de assimetria informacional nos mercados e procura evidenciar como tal assimetria pode ser reduzida com a sinalização de mais informação (Spence, 1973). Além de sua importante aplicação em diversas disciplinas, desde antropologia até a zoologia (Bird \& Smith, 2005), a teoria da Sinalização tem frequentemente sido utilizada na literatura sobre empreendedorismo, em que pesquisadores examinam o valor dos sinais produzidos pelas características do conselho (Certo, 2003), envolvimento do fundador e a presença de fundos de Private Equity e Venture capitalists (Megginson \& Weiss, 1991; Brav \& Gompers, 1997; Minardi et al., 2013).

Megginson e Weiss (1991) encontram evidências que sugerem que os gestores de PE/VC reduzem a assimetria informacional entre os participantes do IPO (empresa ofertante, underwriter e investidores), possibilitando IPOs com menor underpricing e menores custos de colocação, maximizando o valor líquido captado pela empresa. Além disso, os resultados apontam que os IPOs de empresas financiadas por PE/VC ocorrem com menor idade da empresa e são capazes de atrair underwriters e auditores mais prestigiados, despertando maior interesse em investidores qualificados.

Meggison e Weiss (1991) justificam que o 'certificado' ou 'credibilidade' PE/VC a IPOs é devido: (i) ao compromisso dos fundos de PE/VC com as empresas investidas após o IPO, mantendo participação relevante no capital delas; (ii) à habilidade dos gestores de PE/VC para construir e manter bons relacionamentos com underwriters, auditores e gestores de investimento; (iii) ao aspecto reputacional das organizações de PE/VC perante o mercado, pois, frequentemente, as organizações gestoras utilizam IPOs como mecanismos de desinvestimento. IPOs bem-sucedidos resultam em melhores desempenhos para os fundos de PE/VC (melhor track-record e maiores chances dos gestores de PE/VC em estruturar novos fundos). Ademais, a reputação favorável e o bom histórico de desempenho (track record) resultam, por meio de IPOs, em desinvestimentos mais rápidos e valores mais 'justos' (Neus \& Walz, 2005).

No Brasil, poucos estudos contemplam a relação entre investimentos de PE/VC e desempenho dos IPOs da BM\&FBovespa. Minardi et al. (2013) avaliaram o desempenho de curto prazo dos IPOs de empresas aportadas por fundos de PE/VC, no mercado brasileiro, no período de 2004 a 2008, e observaram que as empresas investidas por PE/VC obtiveram, em média, underpricing menor e retornos anormais (primeiro ano após o IPO) significativamente superiores à média dos retornos anormais das empresas não investidas. Para os autores, os retornos anormais estão, positivamente, correlacionados com o tamanho da participação desse tipo de investidor. Eles notaram que as empresas investidas por fundos de $\mathrm{PE} /$ VC estão mais bem preparadas para os IPOs devido: à gestão mais profissional; às melhores práticas de governança corporativa; à existência de conselhos de administração mais independentes; e ao alinhamento de interesses entre administração e investidores. 
Por meio de estudos, a partir de uma amostra de IPOs realizados no mercado brasileiro, entre 2004 e 2007, Gioelli (2008) concluiu que as organizações de PE/VC impactam positivamente a governança corporativa das empresas aportadas, diminuindo assim a prática de gerenciamento de resultados contábeis, principalmente próximo à data do IPO, quando as empresas têm seus resultados gerenciados de modo mais intenso. A autora destaca a relevância de uma estrutura de governança corporativa apropriada para a proteção da saúde dos mercados financeiros, dos investidores e dos vários stakeholders, ou seja, das partes interessadas.

Sonoda (2008) não verificou diferenças no desempenho dos IPOs analisados, quando comparados à presença ou não de fundos de $\mathrm{PE} / \mathrm{VC}$. Mediante uma amostra de IPOs na Bovespa, realizados entre 2004 e 2008, o autor constatou não haver evidências estatisticamente expressivas de que a presença de PE/VC influencia o underpricing nos IPOs. Entretanto, o autor observou que as variáveis explicativas relacionadas ao volume captado na oferta e à idade da empresa, da sua constituição ao IPO, são positivamente significativas ao fenômeno do underpricing.

Sob o paradigma da teoria da Sinalização, o que se pretende neste trabalho, é demonstrar que a presença de investimentos de fundos de Private Equity e Venture Capital (PE/VC) nas empresas estreantes na BM\&FBovespa (IPOs) sinaliza para o mercado que esses IPOs podem oferecer qualidade, isto é, retornos, e representar boas oportunidades de investimento, além de comunicar e assegurar, aos interessados, sua qualidade e credibilidade informacional. As 'boas empresas' (com a presença de investimentos de $\mathrm{PE} / \mathrm{VC}$ ) podem oferecer tal garantia, enquanto as 'empresas ruins' (sem a presença de $\mathrm{PE} / \mathrm{VC})$ não podem.

\section{Metodologia}

Por meio de investigações empírico-analíticas, buscou-se analisar a influência da presença de investimentos de fundos de Private Equity e Venture Capital (PE/VC), nas empresas estreantes na BM\&FBovespa (IPOs), sobre a qualidade dos IPOs.

Para isso, aplicou-se um estudo de evento (Mackinley, 1997) visando constatar a existência de retornos anormais acumulados (proxy para qualidade dos IPOs) em carteiras de investimentos compostas por ações provenientes dos IPOs realizados na Bolsa de Valores de São Paulo (BM\&FBovespa), de janeiro/2004 a dezembro/2007.

O período escolhido justifica-se por possibilitar uma análise de longo prazo (até 5 anos) do desempenho dos IPOs de empresas investidas e não investidas por fundos de $\mathrm{PE} / \mathrm{VC}$, abrangendo momentos distintos do mercado acionário brasileiro: um mercado otimista no período de 2004 a 2007, em que os IPOs foram realizados em condições favoráveis para os emitentes; posteriormente, um cenário permeado pela crise dos subprime e por incertezas sobre o desempenho da economia mundial, afetando diretamente o desempenho do mercado acionário brasileiro.

Definiu-se o evento como a data de início de negociação das ações na BM\&FBovespa (IPO). Assim, como Silva e Famá (2011), considerando que não existem cotações das referidas ações em períodos anteriores ao IPO, por se tratar de novas listagens na bolsa, não há condições para o estabelecimento da janela de estimação dos retornos normais. Portanto, o retorno anormal será determinado pela diferença entre o retorno da ação objeto do IPO, a partir da data do evento, e o desempenho do índice Ibovespa.

A partir do evento selecionado, observar-se-á o retorno anormal dos IPOs, tanto das empresas Com_PE/VC como das empresas sem_pe/vc. Os retornos anormais serão verificados para intervalos de um, três e cinco anos (252, 756 e 1260 dias úteis), a partir da data de realização do IPO, o que confere caráter único ao presente estudo frente a outros trabalhos realizados no mercado brasileiro (Silva \& Famá, 2011; Minardi et al., 2013). 
O universo amostral da pesquisa é composto por empresas que realizaram distribuição pública inicial de ações na BM\&FBovespa, no período de janeiro/2004 a dezembro/2007 (106 companhias). Com o objetivo de compor a amostra final com empresas que apresentaram cotações suficientes para o cálculo do retorno anormal, para o período de até cinco anos (1260 dias úteis) após o início de negociação das ações na BM\&FBovespa, foram excluídos os IPOs que não completaram o quinto aniversário de negociação de suas ações na bolsa, contados a partir da data do IPO.

Dessa forma, a amostra final do presente trabalho é composta por 88 IPOs, correspondendo a $72,37 \%$ do montante total arrecadado dos investidores e a $83,02 \%$ da população dos IPOs realizados no período de jan/2004 até dez/2007.

Utilizaram-se cotações de fechamento ajustadas para eventos societários. Os dados necessários para o estudo foram coletados dos prospectos definitivos de oferta pública, ferramenta Economática, Comissão de Valores Mobiliários (CVM) e BM\&FBovespa.

Com a finalidade de verificar um possível papel sinalizador dos fundos de PE/VC sobre o retorno anormal dos IPOs, as carteiras de investimentos foram segmentadas entre empresas que receberam investimentos de fundos de PE/VC (Com_PE/VC) em períodos anteriores ao IPO, e empresas que não receberam aportes de fundos de $\mathrm{PE} / \mathrm{VC}$ (sem_pe/vc) em períodos anteriores à abertura de capital na bolsa. Além disso, criaram-se subgrupos (quartis) das empresas Com_PE/VC, com base no percentual de participação que os fundos de PE/VC detinham sobre o capital das empresas investidas no momento imediatamente anterior ao IPO (part_pevc_PRÉ-ipo). Esse procedimento possibilita verificar a magnitude dos impactos da presença dos fundos de PE/VC sobre a qualidade dos IPOs (proxy retornos anormais).

Tabela 1

Quantidade de IPOs presentes na amostra final

\begin{tabular}{cccccc}
\hline Ano & $\begin{array}{c}\text { Total } \\
\text { de IPOs }\end{array}$ & $\begin{array}{c}\text { Empresas com } \\
\text { PE/VC }\end{array}$ & $\begin{array}{c}\text { Volume captado } \\
\text { (R\$ milhões) }\end{array}$ & $\begin{array}{c}\text { Número médio } \\
\text { de investidores }\end{array}$ & $\begin{array}{c}\text { Nível 2 } \\
\text { e Novo Mercado }\end{array}$ \\
\hline 2004 & 7 & 5 & 4.486 & 5.533 & 7 \\
\hline 2005 & 7 & 3 & 4.021 & 3.940 & 7 \\
\hline 2006 & 18 & 7 & 11.029 & 9.086 & 17 \\
\hline 2007 & 56 & 16 & 39.056 & 10.018 & 43 \\
\hline Total & $\mathbf{8 8}$ & $\mathbf{3 1}$ & $\mathbf{5 8 . 5 9 2}$ & $\mathbf{2 8 . 5 7 7}$ & $\mathbf{7 4}$ \\
\hline
\end{tabular}

A Tabela 1 apresenta informações consolidadas referentes às empresas constantes na amostra final. Nota-se uma evolução do número de IPOs realizados ao longo do período analisado, com destaque para o ano de 2007, que contém mais de $60 \%$ dos IPOs analisados, tanto em quantidade quanto em volume total captado, e o número médio de investidores por IPO nesse mesmo ano é quase o dobro desse número para o ano de 2004.

A Tabela 2 apresenta a estatística descritiva referente a aspectos contábeis, dados de mercado e informações da oferta dos IPOs presentes na amostra final. Percebe-se, estatisticamente, uma homogeneidade entre os grupos de empresas com e sem investimento de fundos de PE/VC, pelo menos em termos médios. O teste $t$ para comparação das médias entre os dois grupos apresentou significância estatística somente para as variáveis Endividamento, percentual da oferta que foi primária e para a variável dummy Governança Corporativa, indicando que o grupo de empresas Com_PE/VC, em relação ao grupo sem_PE/VC, apresentou: (i) menor relação de dívida sobre o patrimônio líquido; (ii) sócios antigos aproveitaram com mais intensidade a emissão para vender sua participação (ou parte dela) na empresa, podendo sugerir o momento de saída (total ou parcial) dos fundos de PE/VC na empresa investida; (iii) emissões somente nos segmentos superiores de Governança Corporativa (Novo Mercado ou Nível 2). 
Tabela 2

Estatística descritiva IPOs - Aspectos contábeis e da oferta

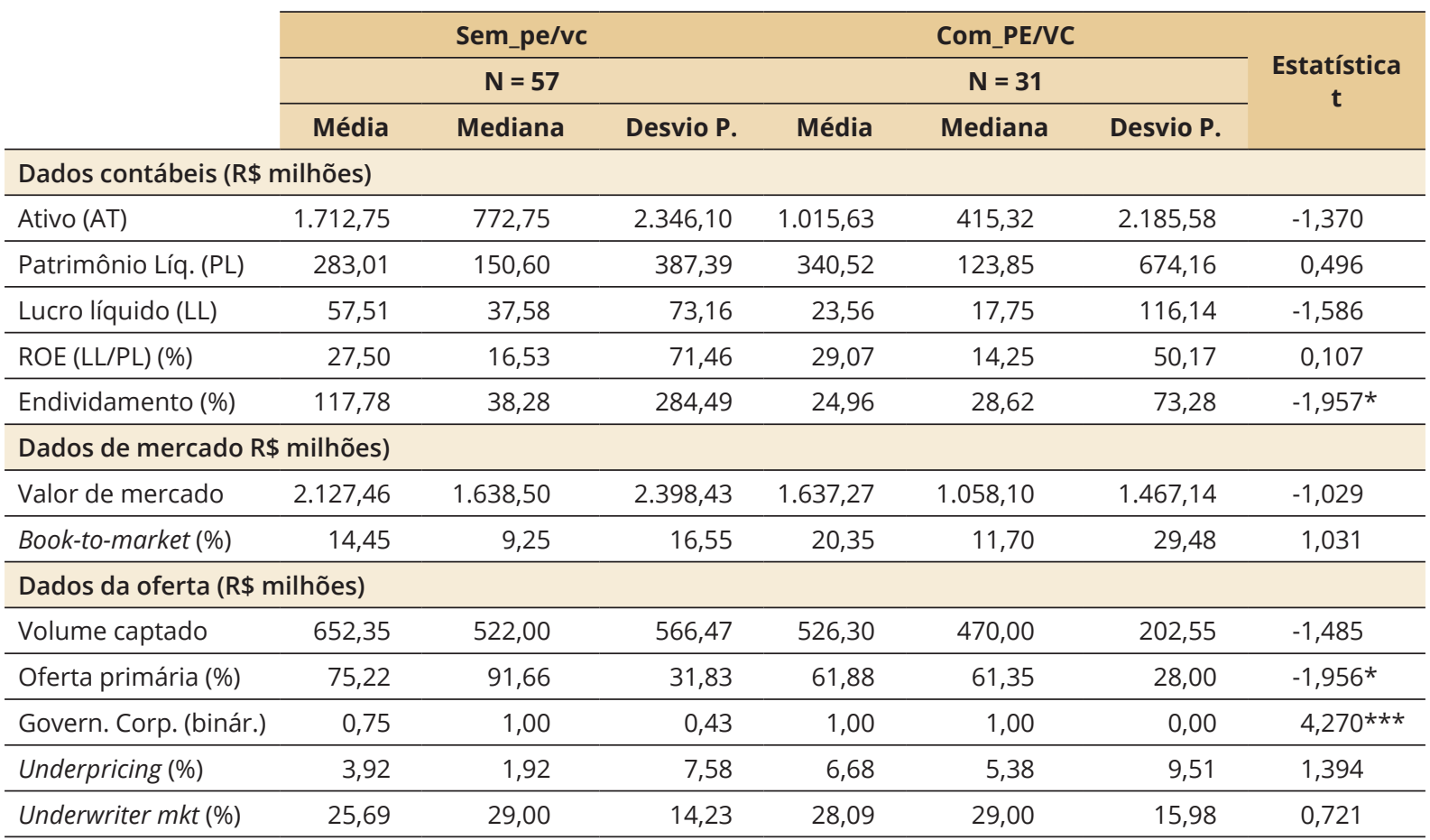

Nota. Os dados contábeis são valores anuais referentes ao ano anterior do IPO. Os dados de mercado e da oferta referem-se a informações na data do IPO. Governança Corporativa igual a 1 para as emissões realizadas no Novo Mercado ou no Nível 2. Underwriter mkt corresponde à participação do mercado de emissões do coordenador líder da oferta no ano do IPO, obtida em Almeida (2011) com base no ranking Anbima. A Estatística $t$ refere-se ao teste $t$ de comparação das médias entre empresas com investimento de PE/VC e das empresas sem investimento.

$*, * *, * * *$ Significância estatística de 10\%,5\% e 1\%, respectivamente.

\subsection{Mensuração do desempenho (retornos anormais acumulados)}

Em conformidade com outros trabalhos (Gompers \& Lerner, 2003; Silva \& Famá, 2011; Minardi et al. 2013) na janela pós-evento, o retorno anormal é determinado pela diferença entre o retorno da ação objeto do IPO e o desempenho de um índice que represente o retorno do mercado. Nesse caso, o Ibovespa:

$$
A R_{-} I p o_{-} I B O V_{i, t}=R_{-} i p o_{i, t}-R_{I B O V, t}
$$

em que $A R \_i p o \_I B O V_{i, t}$ é retorno anormal da ação $i$, presente na amostra final de IPOs, em relação ao benchmark Ibovespa, no período $t$; $R \_i p o_{i, t}$ é o retorno logarítmico da ação $i$ no período $t$; e $R_{I B O V, t}$ é o retorno logarítmico do Índice Ibovespa no período $t$.

Os retornos anormais acumulados ou cumulative abnormal returns (CAR) dos IPOs foram calculados conforme equações a seguir:

$$
C A R_{-} I p o_{-} I B O V_{i, T}=\sum_{t=1}^{T} A R_{-} I p o_{-} I B O V_{i, t}
$$

onde $C A R \_I p o \_I B O V_{i, T}$ é retorno anormal acumulado ação $i$ em relação ao benchmark Ibovespa, do período $t$ até o período $T$. 
Além disso, para os resultados do grupo Com_PE/VC, foram criados subgrupos (quartis) com base no percentual de participação que os fundos de PE/VC detinham sobre o capital das empresas investidas no momento imediatamente anterior ao IPO (part_pevc_PRÉ-ipo). Esse procedimento possibilita verificar a magnitude dos impactos da presença dos fundos de PE/VC sobre a qualidade dos IPOs (proxy retornos anormais).

Para cada grupo ou amostra $j$ (Todos IPOs, Com_PE/VC, sem_pe/vc e part_pevc_PRÉ-ipo) com $\mathrm{n}_{\mathrm{j}}$ ações presentes, calculou-se o CAR médio simples e ponderado pelo valor de mercado do IPO (VM), conforme as equações abaixo:

$$
\begin{aligned}
& \overline{\operatorname{CAR}_{\text {Ipo }_{\text {IBOV }_{J, T}}}}=\frac{\sum_{i=1}^{n_{j}} C A R_{\text {Ipo }_{I B O V} i, j, T}}{n_{j}} \\
& \overline{v m C A R \_I p o \_I B O V_{J, T}}=\frac{\sum_{i=1}^{n_{j}} C A R_{-} I p o_{-} I B O V_{i, j, T} x V M_{i, j}}{\sum_{i=1}^{n_{j}} V M_{i, j}}
\end{aligned}
$$

em que $\overline{C A R \_I p o_{-} I B O V_{J, T}}$ é média simples e $\overline{v m C A R \_I p o_{-} I B O V_{J, T}}$ é a média ponderada do retorno anormal acumulado das ações presentes na amostra $j$, em relação ao benchmark Ibovespa, no período $T$.

\subsection{Teste de médias}

Com o objetivo de constatar diferenças estatisticamente significantes entre os retornos anormais acumulados dos grupos Com_PE/VC e sem_pe/vc para CAR_Ipo_IBOV e vmCAR_Ipo_IBOV, procedeuse o teste $t$ para duas amostras independentes (Anderson, Sweeney, \& Williams, 2007; Minardi et al., 2013):

$$
\text { Estatísticat }=\frac{\overline{X_{\alpha}}-\overline{X_{\beta}}}{\left[\left(s_{X_{\alpha}}^{2} / n_{\alpha}+s_{X_{\beta}}^{2} / n_{\beta}\right)\right]^{1 / 2}}
$$

em que $\overline{X_{\alpha}}$ e $\overline{X_{\beta}}=$ média dos valores das amostras $X_{\alpha}$ e $X_{\beta}$ respectivamente; $s_{X_{\alpha}}^{2}$ e $s_{X_{\beta}}^{2}=$ estimadores das variâncias populacionais de $X_{\alpha}$ e $X_{\beta}$ respectivamente; e $n_{\alpha}$ e $n_{\beta}=$ número de observações na amostra $X_{\alpha}$ e $X_{\beta}$ respectivamente.

Já para os IPOs Com_PEVC segmentados por quartil conforme participação detida pelos fundos de PE/VC (part_pevc_PRÉ-ipo), procedeu-se à análise de variância (analysis of variance) ou ANOVA para verificar se diferentes percentuais de participação detidos pelos fundos de PE/VC apresentam diferenças nos retornos anormais acumulados médios. Por meio da ANOVA, calcula-se a estatística de teste da igualdade de $k$ médias populacionais - Estatística $\mathrm{F}$ (Anderson et al., 2007).

Posteriormente aos testes ANOVA, realizou-se o teste post hoc Tukey's Honest Significant Differences (Tukey), um procedimento estatístico de comparação múltipla usado em conjunção com o ANOVA, para verificar quais médias entre os grupos testados apresentam diferenças significativas entres si.

Para algumas amostras, rejeitou-se a hipótese da normalidade (teste de Kolmogorov-Smirnov). Portanto, além dos testes $t$ e ANOVA, foram realizados os testes não paramétricos Mann-Whitney U para duas amostras independentes e o teste Kruskal-Wallis $H$ para $k$ amostras independentes. 


\subsection{CAPM}

Conforme demonstra Kothari e Warner (1997) e Gompers e Lerner (2003), o capital asset pricing model (CAPM) desenvolvido por Sharpe (1964) e Lintner (1965) é comumente utilizado para estimar o retorno anormal de ativos negociados no mercado.

Entretanto, na literatura nacional, observa-se escassez de trabalhos que realizam tal aplicação do CAPM, para verificação dos retornos anormais de empresas investidas por fundos de PE/VC.

Este trabalho aplica o CAPM adaptado para o cenário brasileiro, conforme método proposto pelo Centro de Estudos de Mercados de Capitais [CEMEC] (2013), com o objetivo de verificar se, mesmo após o controle do risco (beta), o desempenho dos IPOs com a presença de fundos de PE/VC apresentou resultados positivos e significantes.

Para isso, o retorno da ação $i$ presente na amostra $j$ (Todos IPOs ou IPOs Com_PEVC ou IPOs sem_ pevc), menos o retorno de uma taxa livre de risco, é regredido contra o fator desempenho do mercado menos o retorno de uma taxa livre de risco (prêmio pelo risco do mercado) e o fator risco soberano brasileiro:

$$
R_{-} i p o_{i, j, m}-T B O N D_{m}=\alpha+\beta_{1}\left(S \& P 500_{m}-T B O N D_{m}\right)+\beta_{2} E M B I_{m}+\varepsilon
$$

onde: $R \_i p o_{i, j, m}=$ retorno mensal em dólares americanos (USD) da ação $i$ presente na amostra $j$, referente ao mês $m ; T_{B O N D}=$ retorno mensal em USD do título norte-americano Treasury Bond 10 years no mês $m ; S \& P 500_{m}=$ retorno mensal em USD do índice Standard \& Poor's 500 no mês $m ; E M B I_{m}=$ prêmio mensal pelo risco soberano brasileiro $\left(E M B I+\right.$ Brasil), no mês $m ; \alpha, \beta_{1}$ e $\beta_{2}=$ parâmetros estimados na regressão; $\varepsilon=$ termo de erro da regressão.

O parâmetro de interesse na regressão é o coeficiente $\alpha$ (alfa). O sinal positivo e significante indica que, após o controle do prêmio pelo risco de mercado e pelo risco soberano do Brasil, as ações da amostra $j$ apresentaram um retorno superior ao esperado.

Adicionou-se no modelo proposto (6) uma variável dummy dPEVC, possibilitando efetuar a regressão com todos os IPOs da amostra final, controlando pela influência dos fundos de PE/VC.

\subsection{Regressões CAR}

Para verificar se a presença dos fundos de PE/VC explicam o retorno anormal dos IPOs em relação ao benchmark Ibovespa (CAR_Ipo_IBOV), foram utilizadas modelos de regressões ordinary least squares $(O L S)$, conforme as equações propostas abaixo:

$$
C A R_{-} I p o_{-} I B O V_{i, T}=\alpha+\beta_{n} V A R_{i}+\varphi d P E V C_{i}+\varepsilon
$$

em que: $C A R \_I p o \_I B O V_{i, T}=$ retorno anormal acumulado (CAR) da ação $i$ em relação ao benchmark Ibovespa no período $T ; V A R_{i}=$ variáveis de controle do modelo proposto; $d P E V C_{i}=$ assume valor 1 se empresa $i$ recebeu investimentos de fundos de $\mathrm{PE} / \mathrm{VC}$ em períodos anteriores ao IPO (Com PE/VC), e valor 0 se não recebeu (sem pe/vc); $\alpha, \beta_{n}$ e $\varphi=$ parâmetros estimados na regressão; $\varepsilon=$ termo de erro da regressão.

Dada a abrangência temporal de longo prazo ( 5 anos) das análises realizadas no presente trabalho, no modelo proposto, utiliza-se das variáveis de controle (VAR) indicadas no Figura 1, conforme proposto na literatura internacional, com objetivo de controlar por diferenças e alterações de outras variáveis, que possam influenciar os resultados finais das regressões. 


\begin{tabular}{|c|c|c|}
\hline $\begin{array}{c}\text { Variável } \\
\text { controle (VAR) }\end{array}$ & Explicação & $\begin{array}{c}\text { Autores que utilizaram } \\
\text { a variável }\end{array}$ \\
\hline InOFER $_{\mathrm{i}}$ & Logaritmo natural do valor da oferta do IPO & $\begin{array}{l}\text { Barry et al. (1990); } \\
\text { Brav e Gompers (1997); } \\
\text { Minardi et al. (2013) }\end{array}$ \\
\hline $\operatorname{lnVM}_{\mathrm{i}}$ & Logaritmo natural do valor de mercado da empresa no momento do IPO & Minardi et al. (2013) \\
\hline BTM $_{i}$ & Relação valor patrimonial contábil sobre valor de mercado (book-to-market) & $\begin{array}{l}\text { Brav e Gompers (1997); } \\
\text { Minardi et al. (2013) }\end{array}$ \\
\hline Endiv $_{i}$ & Dívida líquida sobre Patrimônio Líquido (Endividamento) & Minardi et al. (2013) \\
\hline InInvest $_{i}$ & Logaritmo natural do número de investidores participantes da oferta & Minardi et al. (2013) \\
\hline PRIM $_{i}$ & Percentual da oferta que foi primária & Fortes, Silveira e Bacic (2012) \\
\hline UnderW $_{\mathrm{i}}$ & $\begin{array}{l}\text { Participação do mercado de emissões do coordenador líder da oferta } \\
\text { no ano do IPO, obtida em Almeida (2011) com base no ranking Anbima } \\
\text { (underwriter_marketshare). }\end{array}$ & $\begin{array}{l}\text { Megginson e Weiss (1991); } \\
\text { Carter et al. (1998) }\end{array}$ \\
\hline dummySETOR & Variáveis dummy conforme o setor de atuação da empresa & \\
\hline
\end{tabular}

Figura 1. Variáveis de controle (VAR) utilizadas na regressão CAR contra dPEVC

Na regressão proposta, o parâmetro de interesse na regressão é o coeficiente $\varphi$ (phi). O sinal positivo e significante indica que, após controle das variáveis selecionadas (VAR), a presença de fundos de PE/VC explica um retorno anormal positivo dos IPOs para o período analisado.

Assim como Barry et al. (1990) e Minardi et al. (2013), o presente trabalho também apresenta uma regressão somente para a amostra de IPOs que receberam investimentos de PE/VC (Com_PEVC):

$$
C A R_{-} I p o_{-} I B O V_{i, T}=\alpha+\beta_{n} V A R_{i}+\delta_{m} V A R 2_{i}+\theta P a r t_{-} P E V C_{-} P R E i p o_{i}+\varepsilon
$$

Em que: $C A R \_I p o \_I B O V_{i, T}=$ retorno anormal acumulado (CAR) da ação $i$ em relação ao benchmark Ibovespa, considerando somente os IPOs Com_PEVC, no período $T ; V A R_{i}=$ variáveis de controle utilizadas no modelo anterior; $V A R 2_{i}=$ variáveis de controle adicionadas no modelo proposto; Part_PEVC_PREipo ${ }_{i}=$ participação acionária detida pelo fundo de $\mathrm{PE/VC} \mathrm{na} \mathrm{empresa} i$ no momento imediatamente ANTERIOR ao IPO; $\alpha, \beta_{n}, \delta_{m}$ e $\theta=$ parâmetros estimados na regressão; $\varepsilon=$ termo de erro da regressão.

A Figura 2 apresenta as variáveis adicionadas nesse segundo modelo (VAR2).

\begin{tabular}{lll}
\hline $\begin{array}{c}\text { Variável controle } \\
\text { (VAR2) }\end{array}$ & \multicolumn{1}{c}{ Explicação } & $\begin{array}{c}\text { Autores que utilizaram a } \\
\text { variável }\end{array}$ \\
\hline Temp_Invest & $\begin{array}{l}\text { Tempo em meses que o fundo de PE/VC investiu na empresa antes } \\
\text { de realizar o IPO }\end{array}$ & $\begin{array}{l}\text { Barry et al. (1990) e Minardi } \\
\text { et al. (2013) }\end{array}$ \\
\hline Temp_Atuacao_Br & $\begin{array}{l}\text { Tempo aproximado (em meses) que o fundo PE/VC atuou no } \\
\text { Brasil até IPO, ou seja, data do primeiro investimento do fundo em } \\
\text { empresas no Brasil, conforme GVcepe-Endeavor (2008). }\end{array}$ & Minardi et al. (2013) \\
\hline dOrigem_PE/VC & $\begin{array}{l}\text { Origem do fundo de PE/VC, assumindo o valor 0 para fundos } \\
\text { brasileiros e 1 para fundos internacionais }\end{array}$ & Minardi et al. (2013) \\
\hline
\end{tabular}

Nota. As informações foram obtidas por meio dos prospectos e do guia GVcepe-Endeavor (2008).

1 Minardi et al. (2013) utilizam a idade do(a) fundo/gestora de PE/VC.

Figura 2. Variáveis controle (VAR2) para regressão de CAR: Part_PEVC_PRE-ipo

A verificação da presença de outliers (observações influentes) foi realizada por meio dos gráficos de boxplots. Para as variáveis que apresentaram grande quantidade de outliers, procedeu-se ajuste pelo método de winsorização (National Institute of Standards and Technology/Semiconductor Manufacturing Technology [Nist/Sematech], 2013). 


\section{Resultados}

A Tabela 3 apresenta as médias dos retornos anormais acumulados dos IPOs presentes na amostra final em relação ao benchmark Ibovespa e o teste de diferenças de médias entre empresas que receberam investimentos de fundos de $\mathrm{PE} / \mathrm{VC}$ em períodos anteriores ao IPO (Com_PE/VC) e empresas que não receberam tais aportes (sem_pe/vc).

Tabela 3

\section{Retorno Anormal Acumulado - IPOs versus benchmark IBOV}

\begin{tabular}{|c|c|c|c|c|c|}
\hline \multicolumn{6}{|c|}{ Painel A - IPOs realizados no período de 2004 até 2007} \\
\hline \multirow{2}{*}{ Dias úteis após IPO } & \multicolumn{5}{|c|}{$\overline{C A R \_I p o \_I B O V}(\mathrm{em} \%)$} \\
\hline & Todos IPOs & sem_pe/vc & Com_PE/VC & Estatística t & Estatística Z \\
\hline 252 & $(36,70)$ & $(48,28)$ & $(15,41)$ & $20,038^{* * *}$ & $15,823 * * *$ \\
\hline 756 & $(44,78)$ & $(51,85)$ & $(31,78)$ & $28,797 * * *$ & $23,320 * * *$ \\
\hline 1260 & $(39,46)$ & $(46,24)$ & $(26,98)$ & $40,244^{* * *}$ & $34,162 * * *$ \\
\hline \multicolumn{6}{|c|}{ Painel B - IPOs realizados no período de 2004 até 2007} \\
\hline \multirow{2}{*}{ Dias úteis após o IPO } & \multicolumn{5}{|c|}{$\overline{V M}$ _car_ipo_ibov (em \%) } \\
\hline & Todos IPOs & sem_pe/vc & Com_PE/VC & Estatística t & Estatística Z \\
\hline 252 & $(26,25)$ & $(35,55)$ & $(4,03)$ & $22,436 * * *$ & $15,964 * * *$ \\
\hline 756 & $(34,27)$ & $(40,24)$ & $(19,99)$ & $42,843^{* * *}$ & $26,804^{* * *}$ \\
\hline 1260 & $(21,42)$ & $(20,67)$ & $(23,21)$ & $43,403 * * *$ & $34,544 * \star \star$ \\
\hline
\end{tabular}

Nota. A Estatística t refere-se ao teste t de comparação das médias. A Estatística Z refere-se ao teste não paramétrico Mann-Whitney-U.

*,**,*** Significância estatística de $10 \%, 5 \%$ e $1 \%$ respectivamente.

Conforme Tabela 3, observa-se que, para o período analisado, em média, os IPOs de empresas Com_PE/VC apresentaram desempenhos superiores em relação às empresas sem_pe/vc. Para os períodos analisados, os resultados dos testes de médias indicam que os retornos entre os grupos Com_PE/VC e sem_ pe/vc apresentam diferenças significativas para um nível de significância de $1 \%$. Nota-se que o desempenho médio das empresas que abriram capital, inclusive de companhias que receberam investimentos de fundos de PE/VC, foi inferior ao desempenho do índice Ibovespa.

\section{A - IPOs de 2004 até 2007}

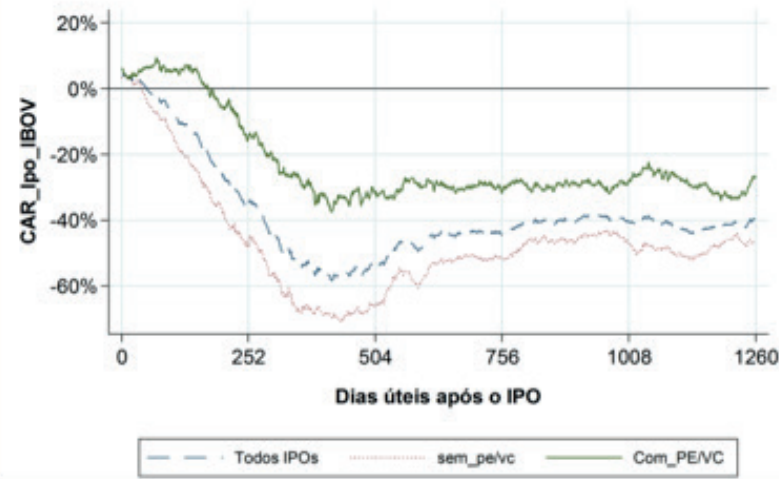

\section{B - IPOs de 2004 até 2007}

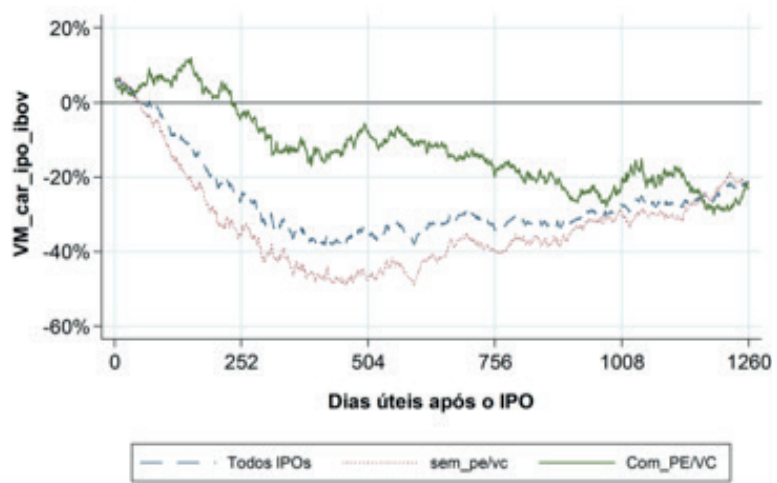

Figura 3. Gráficos Retorno Anormal Acumulado - IPOs versus benchmark IBOV 
A Figura 3 mostra que o retorno médio das amostras analisadas foi inferior ao benchmark IBOV. Tal resultado pode ser reflexo do período estudado, pois os desempenhos posteriores ao ano de 2007 sofreram elevado impacto da crise dos subprimes, e possivelmente, grandes investidores que direcionaram recursos para os IPOs necessitaram cobrir suas posições em outros mercados e/ou buscar ativos com menor volatilidade e/ou maior liquidez, o que impactou, de forma mais intensa, o desempenho de empresas com histórico recente na bolsa (IPOs), em relação às empresas tradicionais (blue chips) que integram o índice Ibovespa.

Verifica-se que, ao longo do período analisado, a média dos retornos anormais acumulados dos IPOs Com_PE/VC é superior ao desempenho tanto dos IPOs sem_pe/vc como de todos os IPOs da amostra. Observa-se que os retornos anormais acumulados ponderados pelo valor de mercado do IPO (Gráfico B, Figura 3) apresentam desempenhos superiores ao do retorno anormal acumulado sem ponderação (Gráfico A, Figura 3).

Tabela 4

Retorno Anormal Acumulado (CAR_Ipo_IBOV): somente IPOs Com_PEVC

\begin{tabular}{|c|c|c|c|c|c|c|}
\hline \multicolumn{7}{|c|}{ Painel C - IPOs realizados no período de 2004 até 2007} \\
\hline \multirow{2}{*}{$\begin{array}{c}\text { Dias úteis após } \\
\text { O IPO }\end{array}$} & \multicolumn{6}{|c|}{ 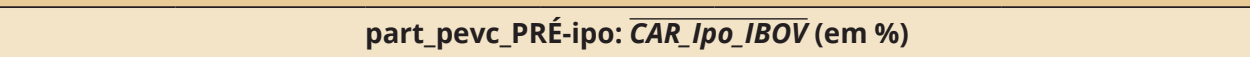 } \\
\hline & $1^{\circ}$ Quarto & $2^{\circ}$ Quarto & $3^{\circ}$ Quarto & $4^{\circ}$ Quarto & Estatística F & Chi-quadrado $\chi^{2}$ \\
\hline 252 & $(18,65)$ & $(16,99)$ & $(33,73)$ & 5,46 & $234,790 * * *$ & $511,235 * * *$ \\
\hline 756 & $(29,49)$ & $(68,27)$ & $(34,39)$ & 4,69 & $789,110 * * *$ & $1440,844 * \star \star$ \\
\hline 1260 & $(42,94)$ & $(42,97)$ & $(8,83)$ & $(10,94)$ & $1854,415^{\star \star \star}$ & $2666,393 * * *$ \\
\hline \multicolumn{7}{|c|}{ Painel D - IPOs realizados no período de 2004 até 2007} \\
\hline \multirow{2}{*}{$\begin{array}{c}\text { Dias úteis após } \\
\text { o IPO }\end{array}$} & \multicolumn{6}{|c|}{ part_pevc_PRÉ-ipo: $\overline{V M}$ _car_ipo_ibov (em \%) } \\
\hline & $1^{\circ}$ Quarto & $2^{\circ}$ Quarto & $3^{\circ}$ Quarto & $4^{\circ}$ Quarto & Estatística F & Chi-quadrado $\chi^{2}$ \\
\hline 252 & $(1,53)$ & $(7,47)$ & $(36,10)$ & 8,15 & $105,369 * * *$ & $362,589 * * \star$ \\
\hline 756 & $(17,92)$ & $(52,21)$ & $(26,36)$ & $(0,59)$ & $779,598^{* * *}$ & $1465,471 * * \star$ \\
\hline 1260 & $(50,98)$ & $(21,25)$ & 4,87 & $(10,20)$ & $1054,121 * \star *$ & $2336,706 * \star \star$ \\
\hline
\end{tabular}

Nota. A Estatística t refere-se ao teste t de comparação das médias. A Estatística Z refere-se ao teste não paramétrico Mann-Whitney-U.

*, **, *** Significância estatística de 10\%,5\% e 1\%, respectivamente.

A Tabela 4 apresenta as médias dos retornos anormais acumulados em relação ao benchmark Ibovespa, somente para IPOs que receberam investimentos de fundos de PE/VC, segmentados por quartos, conforme a participação acionária detida pelo fundo de PE/VC na empresa, no momento imediatamente anterior ao IPO (part_pevc_PRÉ-ipo). Além disso, essa tabela exibe os resultados dos testes estatísticos que verificam se os retornos entre os quartos apresentaram diferenças significativas.

Os resultados indicam que as médias dos retornos anormais entre os quartos, conforme part_pevc_ PRÉ-ipo, apresentam diferenças estatisticamente significantes ao nível de $1 \%$.

Os resultados apresentados na Tabela 4 sugerem que os quartos superiores de part_pevc_PRÉipo apresentam melhores desempenhos em relação aos quartos inferiores. Para uma melhor análise, os gráficos C e D da Figura 4 mostram a evolução das médias dos retornos anormais, considerando somente os quartos part_pevc_PRÉ-ipo das extremidades ( $1^{\circ}$ e $4^{\circ}$ quarto $)$. 


\section{C - IPOs de 2004 até 2007}

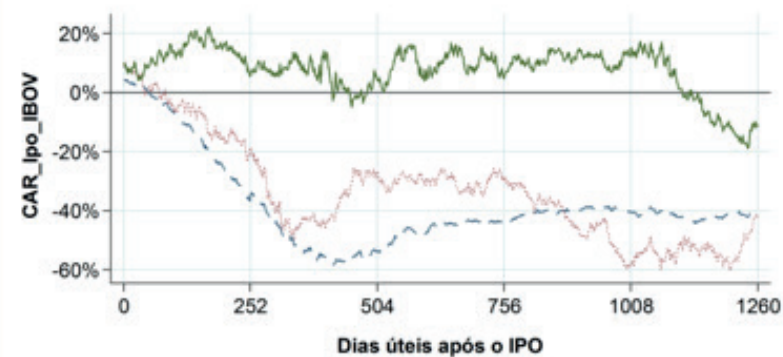

Todos IPOs

1 - Quarto Participaçä PENC Pre-HPO

4. Quarto Participaça PENC Pre.-IPO
D - IPOs de 2004 até 2007

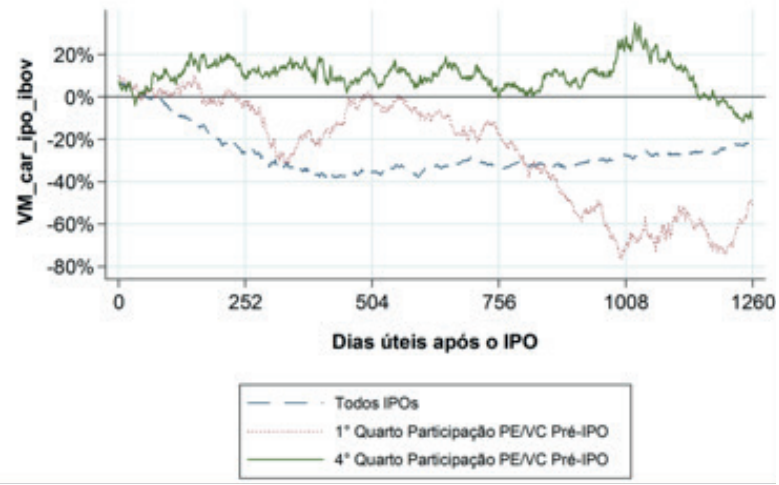

Figura 4. Gráficos Retorno Anormal Acumulado: somente IPOs Com_PEVC

Os Gráficos C e D apresentados na Figura 4 demonstram que os quartos superiores de part_pevc_PRÉipo ( $4^{\circ}$ quarto) exibem os melhores desempenhos, superando tanto os IPOs da amostra final (Todos IPOs) como o quartil mais inferior da participação dos fundos PE/VC. É importante destacar que, para determinados períodos de análise, o quarto superior apresentou retornos positivos, ou seja, superou o índice Ibovespa.

Assim, como nas análises anteriores, observa-se que a média dos retornos do $4^{\circ}$ quarto, ponderados por valores de mercado, tem um desempenho ligeiramente superior em relação às médias dos retornos não ponderados. Tal padrão não pode ser observado tão facilmente para os resultados do $1^{\circ}$ quarto.

As Tabelas 5 e 6 apresentam os resultados da aplicação do CAPM, adaptado para o cenário brasileiro, conforme método proposto pelo Centro de Estudos de Mercados de Capitais [CEMEC] (2013), com o objetivo de verificar se, mesmo após o controle do risco, o desempenho dos IPOs com a presença de fundos de PE/VC apresentou resultados positivos e significantes.

Tabela 5

Matriz de correlação: variáveis CAPM

\begin{tabular}{ccccc}
\cline { 2 - 4 } & (R_ipo $_{i, m}-$ TBOND $\left._{m}\right)$ & Prêmio pelo risco & EMBI+ & Dummy PE/VC \\
\hline$\left(R_{-} i p o_{i, m}-\right.$ TBOND $\left._{m}\right)$ & & $0,514^{* \star *}$ & $(0,126)^{\star * *}$ & 0,017 \\
\hline Prêmio pelo risco & $0,487^{* * *}$ & & $(0,363)^{\star * *}$ & 0 \\
\hline EMBI+ & $(0,087)^{* \star *}$ & $(0,279)^{* * *}$ & & $0,047^{* * *}$ \\
\hline Dummy PE/VC & 0,013 & $(0,002)$ & $0,036^{* * *}$ & \\
\hline
\end{tabular}

Nota. O lado superior direito acima da linha diagonal apresenta a matriz de correlação de Pearson, o lado oposto inferior apresenta a matriz de correlação de Spearman. Valores negativos entre parênteses.

*, **, *** Significância estatística de 10\%, 5\% e 1\%, respectivamente.

Conforme a matriz de correlação das variáveis do modelo proposto, observa-se relação linear positiva e significante entre: o retorno do IPO e o prêmio pelo risco (beta); a presença de fundos de PE/ VC com o risco país (EMBI+). Notam-se relações negativas significantes entre o EMBI+ tanto com o retorno do IPO como do prêmio pelo risco. 
Tabela 6

Regressões CAPM

\begin{tabular}{|c|c|c|c|c|}
\hline \multirow[b]{2}{*}{ Variáveis } & \multicolumn{4}{|c|}{ Variável dependente: $\left(R_{-} i p o_{i, m}-T_{B O N D_{m}}\right)$} \\
\hline & $\begin{array}{c}\text { (1) } \\
\text { Todos IPOs }\end{array}$ & $\begin{array}{c}(2) \\
\text { sem pe/vc }\end{array}$ & $\begin{array}{c}\text { (3) } \\
\text { Com PE/VC }\end{array}$ & $\begin{array}{c}(4) \\
\text { Todos IPOs }\end{array}$ \\
\hline \multirow{2}{*}{ Constante } & $-0,0269 * * *$ & $-0,0287 * \star *$ & $-0,0230 * \star$ & $-0,0280 * * *$ \\
\hline & $(0,00595)$ & $(0,00768)$ & $(0,00942)$ & $(0,00601)$ \\
\hline \multirow{2}{*}{ Prêmio pelo risco } & $1,366^{* * *}$ & $1,363 * * *$ & $1,368 * * *$ & $1,365^{\star * *}$ \\
\hline & $(0,0316)$ & $(0,0393)$ & $(0,0531)$ & $(0,0316)$ \\
\hline \multirow{2}{*}{ Risco País (EMBI+) } & $16,38 * * *$ & $16,56 * \star *$ & $15,71 * * *$ & $16,23^{* * *}$ \\
\hline & $(3,020)$ & $(3,947)$ & $(4,696)$ & $(3,025)$ \\
\hline \multirow{2}{*}{ Dummy PE/VC } & & & & 0,00393 \\
\hline & & & & $(0,00333)$ \\
\hline Observações & 5.280 & 3.420 & 1.860 & 5.280 \\
\hline R Quadrado & 0,269 & 0,266 & 0,277 & 0,270 \\
\hline \multicolumn{5}{|l|}{ Ramsey RESET (p-valor) } \\
\hline H0: modelo não possui variáveis omitidas & $0,005^{\star * \star}$ & $0,04 * *$ & $0,016 * *$ & $0,004 * * *$ \\
\hline Variance inflation factor (VIF) & 1,14 & 1,14 & 1,14 & 1,1 \\
\hline
\end{tabular}

Nota. Regressão (1) refere-se a todos os IPOs da amostra final (88 IPOs); regressão (2) e (3) são referentes aos IPOs sem_pe/vc (57 IPOs) e Com_PEVC (31 IPOs) respectivamente; e a regressão (4) considera todos os IPOs da amostra final utilizando uma variável dummy para IPOs Com_PEVC. Retornos referem-se ao período do $1^{\circ}$ mês após o IPO até o $60^{\circ}$ mês após o IPO, totalizando 60 observações por IPO. Os valores das estatísticas $t$ robustas à heterocedasticidade pelo método de correção de White (1980) são apresentadas entre parênteses.

*, **, *** Significância estatística de 10\%,5\% e 1\%, respectivamente.

Os resultados das regressões indicam que o intercepto apresentou sinal negativo e significante, sugerindo que o retorno observado foi inferior ao retorno esperado, dado o nível de risco assumido. Na regressão (4) (Tabela 6), nota-se que a variável dummy PE/VC apresenta sinal positivo, porém não significante. Esses resultados implicam que a presença de fundos de PE/VC nos IPOs não influencia positivamente o retorno dos IPOs após controle do risco.

$\mathrm{O}$ intercepto negativo e significante corroboram o argumento de que a crise financeira mundial impactou de forma mais intensa o desempenho de empresas com histórico recente na bolsa (IPOs), em relação às empresas tradicionais e com maior liquidez.

As Tabelas 7, 8 e 9 apresentam os resultados dos modelos de regressões CAR para verificar se a presença dos fundos de PE/VC explicam o retorno anormal dos IPOs. 
Tabela 7

Matriz de correlação: IPOs Com e sem PE/VC

\begin{tabular}{|c|c|c|c|c|c|c|c|c|c|c|c|}
\hline & c252d & c756d & c1260d & dPEVC & InOffer & InVM & BTM & Endiv & InInvest & PRIM & UnderW \\
\hline c252d & & $\begin{array}{c}0,505 \\
\star \star \star\end{array}$ & $\begin{array}{c}0,560 \\
\star \star \star\end{array}$ & $\begin{array}{c}0,236 \\
\star \star \star\end{array}$ & 0,072 & $\begin{array}{c}0,200 \\
*\end{array}$ & $(0,007)$ & $(0,125)$ & 0,159 & $\begin{array}{c}(0,325) \\
\star \star \star\end{array}$ & 0,150 \\
\hline c756d & $\begin{array}{c}0,504 \\
\star \star \star\end{array}$ & & $\begin{array}{c}0,763 \\
\star \star \star\end{array}$ & 0,146 & 0,120 & 0,151 & 0,043 & 0,019 & $(0,031)$ & $\begin{array}{c}(0,246) \\
\star \star \star\end{array}$ & 0,128 \\
\hline c1260d & $\begin{array}{c}0,385 \\
\star \star \star\end{array}$ & $\begin{array}{r}0,751 \\
\star \star \star\end{array}$ & & 0,077 & 0,022 & 0,149 & 0,044 & $(0,075)$ & 0,105 & $\begin{array}{c}(0,191) \\
\star \star \star\end{array}$ & 0,036 \\
\hline dPEVC & $\begin{array}{c}0,232 \\
\star * *\end{array}$ & 0,149 & 0,009 & & $(0,083)$ & $(0,130)$ & 0,129 & $(0,111)$ & 0,047 & $\begin{array}{c}(0,206) \\
\star \star\end{array}$ & 0,077 \\
\hline InOFER' & 0,157 & 0,155 & 0,053 & $(0,085)$ & & $\begin{array}{r}0,657 \\
\star \star *\end{array}$ & $(0,085)$ & $\begin{array}{c}0,313 \\
\star \star \star\end{array}$ & 0,051 & 0,096 & 0,080 \\
\hline InVM & $\begin{array}{c}0,202 \\
*\end{array}$ & $\begin{array}{c}0,189 \\
*\end{array}$ & $\begin{array}{c}0,179 \\
*\end{array}$ & $\begin{array}{c}(0,188) \\
*\end{array}$ & $\begin{array}{c}0,634 \\
*\end{array}$ & & $(0,092)$ & $\begin{array}{c}0,234 \\
\star *\end{array}$ & 0,133 & $(0,114)$ & 0,136 \\
\hline BTM $^{1}$ & $(0,037)$ & 0,162 & 0,119 & 0,093 & $(0,129)$ & $(0,128)$ & & $(0,043)$ & 0,056 & $(0,063)$ & 0,084 \\
\hline Endiv & 0,138 & 0,086 & $(0,002)$ & 0,011 & $0,205^{1}$ & 0,148 & 0,112 & & $(0,086)$ & 0,048 & 0,045 \\
\hline InInvest & 0,080 & $(0,056)$ & 0,026 & 0,042 & 0,156 & 0,123 & 0,048 & 0,055 & & $\begin{array}{c}(0,185) \\
*\end{array}$ & $\begin{array}{c}(0,187) \\
*\end{array}$ \\
\hline PRIM & $\begin{array}{c}(0,353) \\
\star \star \star\end{array}$ & $\begin{array}{c}(0,247) \\
\star \star\end{array}$ & $\begin{array}{c}(0,178) \\
*\end{array}$ & $\begin{array}{c}(0,260) \\
\star \star\end{array}$ & 0,040 & $(0,098)$ & $(0,146)$ & $(0,037)$ & $(0,174)$ & & $\begin{array}{c}(0,290) \\
\star \star \star *\end{array}$ \\
\hline UnderW & $\begin{array}{c}0,226 \\
\star \star\end{array}$ & 0,113 & 0,083 & $(0,010)$ & 0,075 & 0,122 & 0,089 & 0,098 & $(0,156)$ & $\begin{array}{c}(0,272) \\
\star \star\end{array}$ & \\
\hline
\end{tabular}

Nota. O lado superior direito acima da linha diagonal apresenta a matriz de correlação de Pearson; o lado oposto inferior apresenta a matriz de correlação de Spearman. c252d = retorno Anormal Acumulado (CAR_Ipo_IBOV) do $252^{\circ}$ dia útil após o IPO; $c 756 \mathrm{~d}=$ CAR_Ipo_IBOV do $756^{\circ}$ dia útil após o IPO; c1260d = CAR_Ipo_IBOV do $1260^{\circ}$ dia útil após o IPO; dPEVC = variável dummy PEVC, que assume valor de 1 para empresas Com_PE/VC e valor 0 para sem_pe/vc; InOFER = logaritmo natural do valor da oferta; InVM = logaritmo natural do valor de mercado da empresa no momento do IPO; BTM = book-to-market, relação valor patrimonial contábil sobre valor de mercado; Endiv = dívida líquida sobre Patrimônio Líquido; InInvest = logaritmo natural do número de investidores; PRIM = percentual da oferta que foi primária; UnderW = participação de mercado do banco coordenador líder da oferta no ano do IPO. Valores negativos entre parênteses.

$*, * *, * * *$ Significância estatística de 10\%,5\% e 1\%, respectivamente.

A matriz de correlação das variáveis (Tabela 7) indica que a presença dos fundos de PE/VC nos IPOs (dummy PE/VC) e o percentual de marketshare do coordernador líder da oferta (underwriter) possuem relação linear positiva e significante com o retorno anormal acumulado (CAR) no primeiro ano (252 dias úteis). Observa-se que a variável dummy $\mathrm{PE} / \mathrm{VC}$ possui relação negativa com o valor de mercado do IPO e o percentual da oferta que foi primária. No entanto, o valor de mercado dos IPOs tem relação positiva e significante com o valor total da oferta, o endividamento, o número de investidores e o retorno anormal acumulado. Quanto ao percentual de oferta primária, nota-se uma relação inversa com o percentual de marketshare do underwriter e também uma relação negativa com o retorno acumulado. 
Tabela 8

Regressão Retorno Anormal Acumulado (CAR) contra presença de fundos de PE/VC no IPO

\begin{tabular}{|c|c|c|c|c|c|c|}
\hline \multirow{3}{*}{ Variáveis } & \multicolumn{3}{|c|}{ sem dummySETOR } & \multicolumn{3}{|c|}{ Com dummySETOR } \\
\hline & (1) & (2) & (3) & (4) & (5) & (6) \\
\hline & c252d & c756d & c1260d & c252d & c756d & c1260d \\
\hline \multirow[t]{2}{*}{ Constante } & $-3,231 *$ & $-3,102$ & $-2,457$ & $-2,515$ & $-3,127$ & $-2,067$ \\
\hline & $(1,887)$ & $(2,439)$ & $(3,708)$ & $(2,147)$ & $(2,822)$ & $(4,392)$ \\
\hline \multirow[t]{2}{*}{ Dummy PEVC } & $0,276 * *$ & 0,159 & 0,136 & $0,270^{*}$ & $0,278 *$ & 0,160 \\
\hline & $(0,116)$ & $(0,132)$ & $(0,213)$ & $(0,139)$ & $(0,164)$ & $(0,257)$ \\
\hline \multirow[t]{2}{*}{ Ln Oferta } & 0,00929 & 0,173 & $-0,185$ & 0,0365 & 0,217 & $-0,293$ \\
\hline & $(0,177)$ & $(0,230)$ & $(0,343)$ & $(0,235)$ & $(0,289)$ & $(0,555)$ \\
\hline \multirow[t]{2}{*}{ Ln Valor Mercado } & 0,182 & 0,0769 & $0,324 * *$ & 0,0959 & 0,0238 & 0,294 \\
\hline & $(0,111)$ & $(0,102)$ & $(0,163)$ & $(0,137)$ & $(0,158)$ & $(0,354)$ \\
\hline \multirow[t]{2}{*}{ Book-to-market } & $-0,135$ & 0,105 & 0,209 & 0,347 & 0,424 & 0,390 \\
\hline & $(0,256)$ & $(0,520)$ & $(0,701)$ & $(0,274)$ & $(0,501)$ & $(0,681)$ \\
\hline \multirow[t]{2}{*}{ Endividamento } & $-0,0794$ & $-0,0103$ & $-0,0860$ & $-0,156$ & $-0,0592$ & $-0,119$ \\
\hline & $(0,107)$ & $(0,0799)$ & $(0,136)$ & $(0,111)$ & $(0,0768)$ & $(0,156)$ \\
\hline \multirow[t]{2}{*}{ Ln Investidores } & 0,0438 & $-0,0509$ & 0,0350 & 0,0910 & $-0,0102$ & 0,123 \\
\hline & $(0,0686)$ & $(0,0552)$ & $(0,126)$ & $(0,0775)$ & $(0,0653)$ & $(0,153)$ \\
\hline \multirow[t]{2}{*}{$\%$ Primária } & $-0,478 * * *$ & $-0,500 * \star$ & $-0,558$ & $-0,493 * *$ & $-0,632 * *$ & $-0,824^{*}$ \\
\hline & $(0,177)$ & $(0,228)$ & $(0,359)$ & $(0,221)$ & $(0,282)$ & $(0,473)$ \\
\hline \multirow[t]{2}{*}{ Market UnderW } & 0,308 & 0,0401 & $-0,199$ & 0,236 & $-0,231$ & $-0,541$ \\
\hline & $(0,398)$ & $(0,506)$ & $(0,690)$ & $(0,446)$ & $(0,589)$ & $(0,911)$ \\
\hline Dummy Setor & & & & 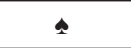 & 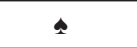 & 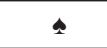 \\
\hline Observações & 88 & 88 & 88 & 88 & 88 & 88 \\
\hline R Quadrado & 0,202 & 0,107 & 0,072 & 0,362 & 0,265 & 0,216 \\
\hline \multicolumn{7}{|l|}{ Ramsey RESET ( $p$-valor) } \\
\hline $\begin{array}{l}\text { H0: modelo não possui var. } \\
\text { omitidas }\end{array}$ & 0,773 & 0,372 & 0,614 & $0 * \star \star$ & 0,255 & $0 * * \star$ \\
\hline Variance inflation factor (VIF) & 1,35 & 1,35 & 1,35 & 5,07 & 5,07 & 5,07 \\
\hline
\end{tabular}

Nota. Regressão OLS das variáveis dependentes: c252d = Retorno Anormal Acumulado (CAR_Ipo_IBOV) do $252^{\circ}$ dia útil após o IPO (1 e 4); c756d = CAR_Ipo_IBOV do $756^{\circ}$ dia útil após o IPO (2 e 5); c1260d = CAR_Ipo_IBOV do $1260^{\circ}$ dia útil após o IPO (3 e 6), referente a 88 IPOs realizados na BM\&FBovespa no período de 2004 até 2007. As regressões (4), (5) e (6) incluem a variável de controle dummySETOR. Variáveis: dPEVC = dummy PEVC, que assume valor de 1 para empresas que receberam investimentos de fundos de PE/VC em períodos anteriores ao IPO (Com PE/VC) e valor 0 para empresas que não receberam tais investimentos (sem pe/vc). Variáveis de controle: InOFER = logaritmo natural do valor da oferta; InVM = logaritmo natural do valor de mercado da empresa no momento do IPO; BTM = book-to-market, relação valor patrimonial contábil sobre valor de mercado; Endiv = dívida líquida sobre Patrimônio Líquido; InInvest = logaritmo natural do número de investidores; PRIM = percentual da oferta que foi primária; UnderW = participação de mercado do banco coordenador líder da oferta no ano do IPO; dummySETOR = 15 variáveis dummy de setor conforme segmento de atuação da empresa. Símbolo indica que resultados das variáveis dummySETOR foram omitidos. Os valores das estatísticas $t$ robustas à heterocedasticidade pelo método de correção de White (1980) são apresentadas entre parênteses.

*,**,*** Significância estatística de 10\%, 5\% e 1\%, respectivamente.

Para as regressões (1), (4) e (5) da Tabela 8, o sinal positivo e significante da variável dummy PE/VC indica que a presença de fundos de $\mathrm{PE} / \mathrm{VC}$ possui efeito positivo sobre o retorno anormal acumulado dos IPOs. Entretanto, para o retornos anormais acumulados de 5 anos após o IPO (regressões 3 e 6 Tabela 8), apesar de o coeficiente da variável dummy $\mathrm{PE} / \mathrm{VC}$ ser positivo, não se pode concluir sobre seu efeito no desempenho dos IPOs, devido à ausência de significância estatística.

Portanto, os resultados indicam que, para a amostra analisada, a presença de fundos de Private Equity e Venture Capital teve influência positiva sobre a qualidade (retorno anormal acumulado) das empresas que abriram capital na bolsa, considerando os desempenhos de até 3 anos após o IPO. 
Tabela 9

Regressão Retorno Anormal Acumulado (CAR): somente IPOs Com_PEVC

\begin{tabular}{|c|c|c|c|c|c|c|}
\hline \multirow{3}{*}{ Variáveis } & \multicolumn{3}{|c|}{ sem dummySETOR } & \multicolumn{3}{|c|}{ Com dummySETOR } \\
\hline & (1) & (2) & (3) & (4) & (5) & (6) \\
\hline & c252d & c756d & c1260d & c252d & c756d & c1260d \\
\hline \multirow[t]{2}{*}{ Constante } & $-4,159$ & $-8,132$ & $-6,554$ & $-12,98 * *$ & $-12,61$ & $-13,00$ \\
\hline & $(3,345)$ & $(5,159)$ & $(6,760)$ & $(4,755)$ & $(9,055)$ & $(9,580)$ \\
\hline \multirow[t]{2}{*}{ Part_PEVC_PREipo } & 0,260 & $0,735 *$ & $1,034 * *$ & $-0,169$ & 1,259 & 1,671 \\
\hline & $(0,304)$ & $(0,374)$ & $(0,492)$ & $(0,756)$ & $(1,361)$ & $(1,760)$ \\
\hline \multirow[t]{2}{*}{ LnOFER } & 0,201 & 0,743 & 0,596 & $-0,479$ & 0,774 & 0,671 \\
\hline & $(0,354)$ & $(0,496)$ & $(0,604)$ & $(0,536)$ & $(0,875)$ & $(1,166)$ \\
\hline \multirow[t]{2}{*}{ InVM } & 0,0343 & $-0,130$ & $-0,167$ & $0,975 * *$ & 0,0265 & 0,0811 \\
\hline & $(0,188)$ & $(0,203)$ & $(0,333)$ & $(0,401)$ & $(0,773)$ & $(1,174)$ \\
\hline \multirow[t]{2}{*}{ BTM } & $-0,397 *$ & $-0,605$ & $-0,578$ & $-0,0756$ & $-0,253$ & $-0,175$ \\
\hline & $(0,230)$ & $(0,369)$ & $(0,516)$ & $(0,438)$ & $(0,881)$ & $(0,960)$ \\
\hline \multirow[t]{2}{*}{ Endiv } & 0,143 & 0,107 & 0,0370 & $-0,127$ & 0,328 & 0,362 \\
\hline & $(0,166)$ & $(0,214)$ & $(0,341)$ & $(0,287)$ & $(0,522)$ & $(0,724)$ \\
\hline \multirow[t]{2}{*}{ InInvest } & 0,0245 & $-0,0447$ & $-0,0906$ & 0,0189 & $-0,0604$ & $-0,0905$ \\
\hline & $(0,0939)$ & $(0,0931)$ & $(0,129)$ & $(0,146)$ & $(0,224)$ & $(0,309)$ \\
\hline \multirow[t]{2}{*}{ PRIM } & $-0,258$ & $-0,634$ & $-0,00110$ & $-0,910 * \star$ & $-1,202$ & $-0,675$ \\
\hline & $(0,438)$ & $(0,405)$ & $(0,732)$ & $(0,390)$ & $(0,790)$ & $(1,215)$ \\
\hline \multirow[t]{2}{*}{ UnderW } & 1,125 & 0,631 & 0,521 & $2,478 * \star$ & 0,436 & 0,524 \\
\hline & $(0,707)$ & $(0,766)$ & $(0,942)$ & $(1,005)$ & $(2,609)$ & $(2,436)$ \\
\hline \multirow[t]{2}{*}{ Temp_Invest } & 0,001 & $-0,003$ & $-0,004$ & $-0,003$ & $-0,011$ & $-0,011$ \\
\hline & $(0,003)$ & $(0,004)$ & $(0,005)$ & $(0,005)$ & $(0,009)$ & $(0,014)$ \\
\hline \multirow[t]{2}{*}{ Temp_Atuacao_Br } & 0,002 & 0,003 & $0,008 * *$ & $0,014 * * *$ & 0,007 & 0,011 \\
\hline & $(0,002)$ & $(0,002)$ & $(0,003)$ & $(0,002)$ & $(0,007)$ & $(0,008)$ \\
\hline \multirow[t]{2}{*}{ dOrigem_PE/VC } & 0,226 & 0,193 & $0,794^{*}$ & $1,258 * * *$ & 0,920 & 1,540 \\
\hline & $(0,260)$ & $(0,316)$ & $(0,413)$ & $(0,305)$ & $(1,117)$ & $(1,250)$ \\
\hline dummySetor & & & & 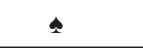 & 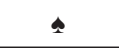 & 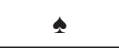 \\
\hline Observações & 31 & 31 & 31 & 31 & 31 & 31 \\
\hline R Quadrado & 0,494 & 0,502 & 0,381 & 0,792 & 0,643 & 0,599 \\
\hline \multicolumn{7}{|l|}{ Ramsey RESET (p-valor) } \\
\hline $\begin{array}{l}\text { H0: modelo não possui var. } \\
\text { omitidas }\end{array}$ & 0,709 & 0,280 & 0,804 & 0,628 & 0,330 & 0,147 \\
\hline Variance inflation factor (VIF) & 1,99 & 1,99 & 1,99 & 15,20 & 15,20 & 15,20 \\
\hline
\end{tabular}

Nota. Regressão OLS das variáveis dependentes: c252d = CAR_Ipo_IBOV do $252^{\circ}$ dia útil após o IPO (1 e 4); c756d = CAR_Ipo_IBOV do $756^{\circ}$ dia útil após o IPO (2 e 5); c1260d = CAR_Ipo_IBOV do $1260^{\circ}$ dia útil após o IPO (3 e 6), considerando somente os IPOs Com_PE/VC. As regressões (4), (5) e (6) incluem a variável de controle dummySETOR. Variáveis: Part_ PEVC_PREipo = participação acionária detida pelo fundo de PE/VC na empresa no momento imediatamente anterior ao IPO. Variáveis de controle: InOFER = logaritmo natural (log) do valor da oferta; InVM = log do valor de mercado da empresa no momento do IPO; BTM = book-to-market, relação valor patrimonial contábil sobre valor de mercado; Endiv = dívida líquida sobre Patrimônio Líquido; InInvest = log do número de investidores; PRIM = percentual da oferta que foi primária; UnderW = participação de mercado do banco coordenador líder da oferta no ano do IPO; Temp_Invest = tempo em meses que o fundo de PE/VC investiu na empresa antes de realizar o IPO; Temp_Atuacao_Br = tempo em meses que o fundo PE/ VC atuou no Brasil até IPO; dOrigem_PE/VC = origem do fundo de PE/VC, assumindo o valor 0 para fundos brasileiros e 1 para fundos internacionais; dummySETOR = 15 variáveis dummy de setor conforme segmento de atuação da empresa. Símbolo indica que resultados das variáveis dummySETOR foram omitidos. Os valores das estatísticas $t$ robustas à heterocedasticidade pelo método de correção de White (1980) são apresentadas entre parênteses.

$*, * \star, * * *$ Significância estatística de $10 \%, 5 \%$ e 1\%, respectivamente. 
A Tabela 9 apresenta os resultados para o modelo de regressão concebido com o propósito de examinar a magnitude da influência dos fundos de PE/VC sobre a qualidade dos IPOs. Ela verifica se uma maior participação acionária dos fundos de PE/VC nas empresas estreantes na BM\&FBovespa implica um maior retorno anormal acumulado dos IPOs.

Observa-se, nas regressões 3 e 4 (Tabela 9), que a origem do fundo de PE/VC e o tempo, em meses, em que ele atuou no Brasil, possuem efeitos positivos e significantes sobre os retornos anormais do $1^{\circ} \mathrm{e}$ $5^{\circ}$ anos após o IPO. Já a participação de mercado do banco coordenador líder da oferta, no ano do IPO, possui influência positiva e significante sobre os retornos anormais somente no $1^{\circ}$ ano após a aberta de capital (regressão 4 Tabela 9).

Os resultados das regressões 2 e 3 (Tabela 9) indicam que a variável de interesse Part_PEVC_PREipo apresentou sinal positivo e com significância estatística. No entanto, para as regressões 1, 5 e 6 (Tabela 9), apesar de o coeficiente da variável apresentar sinal positivo, não foi possível constatar significância estatística.

As informações apresentadas na Tabela 9 permitem verificar a magnitude dos impactos da presença dos fundos de PE/VC sobre a qualidade dos IPOs (proxy retornos anormais), corroborando a hipótese formulada de que quanto maior a participação acionária detida pelo fundo de PE/VC na empresa, no momento imediatamente anterior ao IPO, maior o retorno anormal acumulado para o período de 3 e 5 anos após o IPO.

\section{Conclusão}

O presente trabalho buscou investigar, sob a perspectiva da teoria de Sinalização, o papel certificador dos fundos de Private Equity e Venture Capital (PE/VC) sobre a qualidade das empresas estreantes na BM\&FBovespa (IPOs).

Para isso, propôs-se um estudo de evento visando constatar a existência de retornos anormais acumulados (proxy para qualidade dos IPOs) em carteiras de investimentos compostas por ações provenientes dos IPOs realizados na Bolsa de Valores de São Paulo (BM\&FBovespa), de janeiro/2004 a dezembro/2007.

Os retornos anormais foram determinados pela diferença entre o retorno da ação objeto do IPO, a partir da data de início de sua negociação na BM\&FBovespa, com o desempenho do índice Ibovespa (CAR_ Ipo_IBOV). Com o objetivo de verificar o papel sinalizador (certificador) dos fundos de PE/VC sobre o retorno anormal dos IPOs, as carteiras de investimentos foram segmentadas entre empresas que receberam investimentos de fundos de PE/VC (Com_PE/VC) em períodos anteriores ao IPO e empresas que não receberam aportes de fundos de $\mathrm{PE} / \mathrm{VC}$ (sem_pe/vc) em períodos anteriores à abertura de capital na bolsa. Criaram-se subgrupos (quartis) das empresas Com_PE/VC, com base no percentual de participação que os fundos de PE/VC detinham sobre o capital das empresas investidas no momento imediatamente anterior ao IPO (part_pevc_PRÉ-ipo). Esse procedimento possibilitou verificar a magnitude dos impactos da presença dos fundos de PE/VC sobre a qualidade dos IPOs (proxy retornos anormais).

As hipóteses foram verificadas por meio de três procedimentos distintos: teste de médias; CAPM (capital asset pricing model); e regressões OLS (ordinary least square).

Os resultados dos testes de médias indicaram que, em média, os IPOs de empresas Com_PE/VC apresentaram desempenhos superiores e estatisticamente significantes em relação às empresas sem_pe/ vc, para as médias dos retornos anormais acumulados em relação ao índice Ibovespa ( $\overline{C A R_{-} I p o_{-} I B O V}$ e $\left.\overline{V M \_c a r \_l p o \_l b o v}\right)$. Além disso, para os IPOs Com_PE/VC segmentados por quartil, conforme participação detida pelos fundos de $\mathrm{PE} / \mathrm{VC}$, os resultados demonstraram que o quarto mais superior de part_pevc_PRÉ-ipo exibiu desempenho maior do que o dos IPOs presentes na amostra e dos IPOs do quarto mais inferior da participação dos fundos PE/VC. É importante destacar que, para determinados períodos de análise, o quarto superior apresentou retornos positivos, ou seja, superou o índice Ibovespa. 
Os resultados das regressões CAPM apresentaram interceptos com sinal negativo e significante, sugerindo que os retornos observados foram inferiores ao retorno esperado, dado o nível de risco assumido. No entanto, para o modelo com a inclusão de uma variável dummy PE/VC, o sinal foi positivo, porém não significante. Tal resultado implicou que a presença de fundos de PE/VC nos IPOs não influencia o retorno dos IPOs após controle do risco de mercado e risco país (EMBI+).

As regressões CAR apresentaram sinal positivo e significante para variável dummy PE/VC, indicando que a presença de fundos de PE/VC possui efeito positivo sobre o retorno anormal acumulado dos IPOs. Entretanto, para o retornos anormais acumulados de 5 anos após o IPO, apesar de o coeficiente da variável dummy PE/VC ser positivo, não se pode concluir sobre seu efeito no desempenho dos IPOs, em razão da ausência de significância estatística.

Os resultados das regressões CAR com a variável dummy PE/VC indicaram que a presença de fundos de Private Equity e Venture Capital teve influência positiva sobre a qualidade (retorno anormal acumulado) das empresas que abriram capital na bolsa, considerando os desempenhos de até 3 anos após o IPO.

Para as regressões CAR que verificaram a magnitude do impacto da presença dos fundos de PE/ VC sobre o desempenho dos IPOs, os resultados dos modelos para retornos dos $3^{\circ}$ e $5^{\circ}$ anos após o IPO indicaram que a variável de interesse, Part_PEVC_PRE-ipo, apresentou sinal positivo e significância estatística, indicando que quanto maior a participação acionária detida pelo fundo de $\mathrm{PE} / \mathrm{VC}$ na empresa no momento imediatamente anterior ao IPO maior o retorno anormal acumulado do IPO.

Em síntese, as evidências encontradas neste trabalho mostram que a presença de fundos de PE/VC nas empresas estreantes na BM\&FBovespa certifica a qualidade dos IPOs, e que quanto maior a participação acionária dos fundos de PE/VC nas empresas estreantes na BM\&FBovespa maior a qualidade dos IPOs.

Ao contrário da literatura internacional, em que se observam análises de longo prazo sobre o desempenho de ativos em mercados de capital, a literatura nacional carece de trabalhos com escopos temporais de longo prazo, dada a limitação de dados.

Análises de longo prazo em mercados financeiros são importantes para melhor compreensão de fenômenos e validação de achados teóricos, de forma que contribuam para a evolução do arcabouço teórico e do ferramental prático das pesquisas.

$\mathrm{Na}$ literatura nacional, estudos que analisam o desempenho das empresas investidas por fundos de PE/VC restringem-se à análise temporal para o período de 1 ano. Dessa forma, a presente pesquisa contribui para a incipiente literatura sobre Private Equity e Venture Capital no Brasil, ao realizar um estudo inédito sobre o desempenho de longo prazo dos IPOs, realizados na BM\&FBovespa, que receberam investimentos de fundos de PE/VC, considerando múltiplas técnicas de análise para melhor robustez dos resultados, conforme sugerido e proposto na literatura internacional (Megginson \& Weiss, 1991; Brav \& Gompers, 1997; Kothari \& Warner, 1997; Gompers \& Lerner, 2003).

A pesquisa complementa outros estudos sobre o mercado de Private Equity e Venture Capital no Brasil, que verificaram os impactos positivos da presença dos fundos de PE/VC nas empresas investidas: Gioielli (2008) verificou que as empresas investidas de PE/VC possuem uma melhor governança corporativa e maior qualidade da informação contábil; Sasso (2012) verificou que empresas que receberam aportes de fundos de PE possuem mais qualidade de lucros e menor endividamento em relação às companhias não investidas; Minardi et al. (2013) constataram que o retorno anormal acumulado de curto prazo das empresas investidas de PE/VC apresenta desempenho superiores em relação aos outros IPOs.

Recomenda-se que as próximas pesquisas busquem esclarecer e compreender os possíveis fatores que explicam um desempenho superior dos IPOs que receberam investimentos de fundos de PE/VC. Conforme a evolução e o crescimento do mercado de capitais brasileiros e da indústria de Private Equity e Venture Capital, no Brasil, futuros trabalhos poderão ter acesso a bases de dados mais amplas, representativas e com aspecto temporal mais extenso, permitindo a produção de estudos de qualidade que melhor elucidem a realidade observada. 


\section{Referências}

Almeida, V. S. (2011). Underwriter reputation in brazilian ipos. American Business Review, 12(4), pp. 255-280.

Anderson, D. R., Sweeney, D. J., \& Williams, T. A. (2007). Estatística Aplicada à Administração e Economia. (2 ed.) São Paulo: Thomson.

Barry, C. B., Muscarella, C. J., Peavy, J. W., \& Vetsuypens, M. R. (1990). The role of venture capital in the creation of public companies: evidence from the going-public process. Journal of Financial Economics, 27(2), pp.447- 471.

Bird, R. B., \& Smith, E. A. (2005). Signaling theory, strategic interaction, and symbolic capital. Current Anthropology, 46( 2), pp. 221-248.

Bolsa de Valores de São Paulo. (2013). BM\&FBOVESPA divulga balanço de operações de 2012. Recuperado em 26 abril, 2013, de http://www.bmfbovespa.com.br/pt-br/noticias/2013/download/balanco_1212.pdf

Brav, A., \& Gompers, P. A. (1997). Myth or reality? The long-run underperformance of initial public offerings: evidence from venture and nonventure capital-backed companies. The Journal of Finance. 52(5), pp. 1791-1821.

Carter, R. B., Dark, F. H., \& Singh, A. K. (1998). Underwriter reputation, initial returns, and the long-run performance of IPO stocks. The Journal of Finance, 53(1), pp. 285-311

Centro de Estudos do Instituto Brasileiro de Mercado de Capitais. (2013). Indicadores de custo de capital próprio mensal, março/2013. Recuperado em 26 abril, 2013, de http://www.cemec.ibmec.org.br/ download/INDICADORES_CEMEC_CUSTO_CAPITAL_PROPRIO_MENSAL_Metodos\%20 1\%20e\%202_Mar_2013.pdf

Certo, S. T. (2003). Influencing initial public offering investors with prestige: signaling with board structures. Academy of Management Review, 28(3), pp. 432-446.

Daniel, K., Hirshleifer, D., \& Subrahmanyam, A. (1998). Investor psychology and security market underand overreactions. The Journal of Finance, 53(6), pp. 1839-1885.

Fortes, P. C. B., Silveira, R. L. F., \& Bacic, M. J. (2012). Desempenho das empresas após IPO: análise da importância dos fundos de private equity. Anais do SEMEAD, 15. São Paulo.

Gioielli, S. P. O. (2008). Os gestores de private equity e venture capital influenciam a governança corporativa das investidas? Evidências das empresas estreantes na Bovespa. São Paulo. Dissertação Mestrado em Administração de Empresas - Escola de Administração de Empresas de São Paulo, Fundação Getúlio Vargas, São Paulo, SP, Brasil.

Gompers, P. A., \& Lerner, J. (2003). The really long-run performance of initial public offerings: the prenasdaq evidence. The Journal of Finance, 58(4), p. 1355-1392.

Kothari, S. P., \& Warner, J. B. (1997). Measuring long-horizon security price performance. Journal of Financial Economics, 43, p. 301-339.

Lerner, J., Hardymon, F., \& Leamon, A. (2009). Venture capital and private equity: a casebook. 4th. ed., New Jersey: John Wiley \& Sons.

Lintner, J. (1965). The valuation of risk assets and the selection of risky investments in stock portfolios and capital budgets. The Review of Economics and Statistics, 47(1), pp.13-37.

Mackinlay, A. C. (1997). Event studies in economics and finance. Journal of Economic Literature, 35(1), pp.13-39.

Megginson, W. L., \& Weiss, K. A. (1991). Venture capitalist certification in initial public offerings. Journal of Finance, 46(3), pp. 879-903. 
Minardi, A. M. A. F., Ferrari, G. L., \& Tavares, P. C. A. (2013). Performances of Brazilian IPOs backed by private equity. Journal of Business Research. 66(3), pp. 448-455.

National Institute of Standards and Technology/Semiconductor Manufacturing Technology. (2013). e-Handbook of Statistical Methods. Recuperado em 26 abril, 2013, de http://www.itl.nist.gov/div898/ handbook

Neus, W., \& Walz, U. (2005). Exit timing of venture capitalists in the course of an initial public offering. Journal of Financial Intermediation, 14, pp. 253-277.

Ritter, J. R. (2003). Investment banking and securities issuance. In: Constantinides, G. M., Harris, M., \& Stulz, R. M. Handbook of the economics of finance. Elsevier.

Ritter, J. R., \& Welch, I. (2002). A review of IPO activity, pricing, and allocations. The Journal of Finance, 57(4), pp. 1795-1828.

Sasso, R. C. (2012). Qualidade de lucros e estrutura de propriedade: a indústria de private equity no Brasil. São Paulo. Dissertação Mestrado em Ciências Contábeis - Faculdade de Economia, Administração e contabilidade, Universidade de São Paulo, São Paulo, SP, Brasil.

Sharpe, W. F. (1964). Capital asset prices: a theory of market equilibrium under conditions of risk. The Journal of Finance, 19(3), pp. 425-442.

Silva, J. M. A., \& Famá, R. (2011). Evidências de retornos anormais nos processos de IPO na Bovespa no período de 2004 a 2007: um estudo de evento. Revista de Administração, São Paulo, 46(2), pp. 178-190.

Sonoda, Fabio (2008). Análise da influência do private equity e venture capital no underpricing dos IPOS das empresas brasileiras no período de 2004 a 2007. São Paulo. Dissertação Mestrado em Administração de Empresas - Escola de Administração de Empresas de São Paulo, Fundação Getúlio Vargas, São Paulo, SP, Brasil.

Spence, A. M. (1973). Job market signaling. The Quarterly Journal of Economics, 83(3), pp. 355-374.

Teoh, S. H., Welch, I., \& Wong, T. J. (1998). Earnings management and the long-run market performance of initial public offerings. Journal of Financial, 53(6), pp. 1935-1974. 